\title{
C6-ceramide synergistically potentiates the anti-tumor effects of histone deacetylase inhibitors via AKT dephosphorylation and $\alpha$-tubulin hyperacetylation both in vitro and in vivo
}

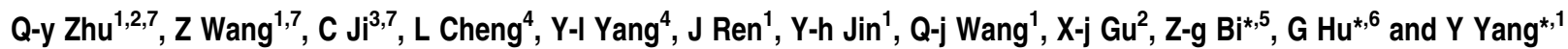

Histone deacetylase inhibitors (HDACls) have shown promising anti-tumor effects for a variety of malignancies, however, many tumors are reportedly resistant to them. In this study, we made a novel discovery that co-administration of HDACls (Trichostatin A (TSA) and others) and exogenous cell-permeable short-chain ceramide (C6) results in striking increase in cancer cell death and apoptosis in multiple cancer cells. These events are associated with perturbations in diverse cell signaling pathways, including inactivation of Akt/mTOR and increase in $\alpha$-tubulin acetylation (both in vivo and in vitro). TSA interacts in a highly synergistic manner with C6-ceramide to disrupt HDAC6/protein phosphatase 1 (PP1)/tubulin complex, to induce $\alpha$-tubulin hyperacetylation, and to release and activate PP1, which then leads to AKT dephosphorylation and eventually causes cancer cell death. Interestingly, TSA itself results in short-term ceramide accumulation, which as a result of metabolic (glycosylation) removal, does not result in evident increase of cancer cell death. However, adding C6-ceramide led to a very pronounced increase in ceramide level and marked increase in cell death. Importantly, the effective synergistic anti-tumor activity of TSA plus C6-ceramide is also seen in in vivo mice xenograft pancreatic and ovarian cancer models, indicating that this regimen (HDACl plus C6-ceramide) may represent a more effective form of therapy against pancreatic and ovarian carcinoma.

Cell Death and Disease (2011) 2, e117; doi:10.1038/cddis.2010.96; published online 27 January 2011

Subject Category: Cancer

In recent years, the importance of epigenetics in cancer development has been appreciated. ${ }^{1}$ Changes in DNA methylation and histone acetylation have been linked to aberrant silencing of multiple tumor suppressor genes from a wide variety of tumors. ${ }^{2}$ An array of drugs with histone deacetylase inhibitors (HDACls) effect has been described and many are currently under clinical trials; some HDACls have been approved by the USA FDA, for example, vorinostat (also known as suberoylanilide hydroxamic acid (SAHA)), has been approved for treatment of T-cell lymphoma. ${ }^{3}$ Although these investigations are actively recruiting patients, to date these agents are well tolerated and efficacious. ${ }^{4}$ The antitumor effects of these drugs are thought to result from hyperacetylation of histones, demethylation of genomic DNA and a resulting reactivation of genes that inhibit proliferation. ${ }^{5,6}$ In addition to these transcriptional effects, inhibitors of deacetylase have also been shown to have significant post-translational effects on non-histone proteins, including tubulin. ${ }^{7}$ Treatment with TSA and other HDACls cause tubulin acetylation and stabilization, which then lead to tumor cell death. ${ }^{8}$ Furthermore, recent studies also indicate that TSA blocks specific interactions of protein phosphatase 1 (PP1) with HDAC6, resulting in increased PP1-Akt association, causing AKT dephosphorylation and inhibition. ${ }^{8}$

Membrane sphingolipids are biologically active and have numerous regulatory effects on cell function, including cell apoptosis, growth and differentiation. ${ }^{9,10}$ Ceramides are a family of lipid molecules, which is composed of sphingosine and a fatty acid. Besides its role as a structural element, ceramides are reported to have strong relationship with apoptosis in tumor cells. ${ }^{11}$ It has been suggested that processes that would enhance intracellular ceramide accumulation would provide favorable proapoptotic outcomes in cancer chemotherapy. ${ }^{12}$ C6-ceramide, a cell-permeable ceramide,

\footnotetext{
1Department of Physiology, China Pharmaceutical University, Nanjing, PR China; ${ }^{2}$ Department of Urology, Jiangsu Province Hospital of TCM, Nanjing, PR China; ${ }^{3}$ Department of Dermatology, the First Affiliated Hospital of Nanjing Medical University, Nanjing, PR China; ${ }^{4}$ Department of Otorhinolaryngology, the First Affiliated Hospital of Nanjing Medical University, Nanjing, PR China; ${ }^{5}$ Department of Dermatology, the Affiliated BenQ Hospital of Nanjing Medical University, Nanjing, PR China and ${ }^{6}$ Jiangsu Province Key Lab of Neurodegeneration, Department of Pharmacology, Nanjing Medical University, Nanjing, PR China

${ }^{*}$ Corresponding author: Y Yang, Department of Physiology, China Pharmaceutical University, Nanjing 210009, PR China. Tel: + 862583271132 ; Fax: + 86025 83271132; E-mail: valianty@ hotmail.com or G Hu, Jiangsu Province Key Lab of Neurodegeneration, Department of Pharmacology, Nanjing Medical University, Nanjing, PR China. Tel: + 8625 86863108; Fax: + 8625 86863108; E-mail: ghu @ njmu.edu.cn or Z-g Bi, Department of Dermatology, the Affiliated BenQ Hospital of Nanjing Medical University, Nanjing 210019, PR China. Tel: + 8625 52238800; E-mail: eltonbibenqhospital@yahoo.com.cn

${ }^{7}$ These authors contributed equally to this work.

Keywords: Trichostatin A; histone deacetylase inhibitors; C6-ceramide; PP1; AKT; Tubulin

Abbreviations: PDMP, 1-phenyl-2-decanoylamino-3-morpholino-1-propanol; CAPP, ceramide-activated protein phosphatase; HDACls, Histone deacetylase inhibitors; MAP, microtubule-associated protein; PP1, Protein Phosphatase 1; SAHA, suberoylanilide hydroxamic acid; SB, sodium butyrate; TSA, Trichostatin A Received 02.9.10; revised 10.12.10; accepted 13.12.10; Edited by A Stephanou
} 
has shown activity against a variety of cancer cell lines. ${ }^{13,14}$ Recent but limited studies have indicated the potential use of ceramides as an adjuvant for traditional chemotherapeutic drugs, such as Taxol, to enhance anti-tumor effects, ${ }^{15,16}$ however, the exact mechanism remains unclear.

In this study, we examined the potential effect of C6-ceramide to augment the anti-tumor effect of TSA in vitro and in vivo. The results indicate that TSA/C6-ceramide combination exerted strong synergistic effects on AKT inhibition and $\alpha$-tubulin hyperacetylation, which may be the key mechanism to cause cancer cell death and apoptosis.

\section{Results}

In vitro synergism of C6-ceramide and TSA in cancer cells death. We first examined the synergism between
TSA and C6-ceramide in killing cancer cells in ovarian cancer cell line $\mathrm{CaOV} 3$ cells and pancreatic cancer cell line L3.6 cells in vitro by using 3-[4,5-dimethylthylthiazol-2-yl]2,5 diphenyltetrazolium bromide (MTT) assay. C6-ceramide, which alone had almost no effect on cancer cell death, markedly enhanced TSA-induced cell death in a dosedependent manner in both CaOV3 (Figures $1 \mathrm{a}$ and $\mathrm{b}$ ) and L3.6 (Figure 1c and d) cells. As shown in Table 1, $100 \mathrm{ng} / \mathrm{ml}$ of TSA alone kills almost $8.4 \%$ CaOV3 after $48 \mathrm{~h}$. In the presence of $10 \mu \mathrm{g} / \mathrm{ml}$ of C6-ceramide (C6-ceramide alone killed $12.9 \%$ CaOV3) however, the same dose of TSA killed $68.3 \%$ of CaOV3 cells (Table 1 ). In CaOV3 cells, TSA's IC ${ }_{50}$ (the dose that kills $50 \%$ of cancer cells) is $414.3 \mathrm{ng} / \mathrm{ml}$, however, in the presence of C6-ceramide $(10 \mu \mathrm{g} / \mathrm{ml})$, its $I_{50}$ dropped to $51.2 \mathrm{ng} / \mathrm{ml}$ (Table 1$)$. Similar results were also seen in other cancer cells (Table 1). Notably, when cells are cultured in $10 \%$ FBS, either C6-ceramide or TSA alone
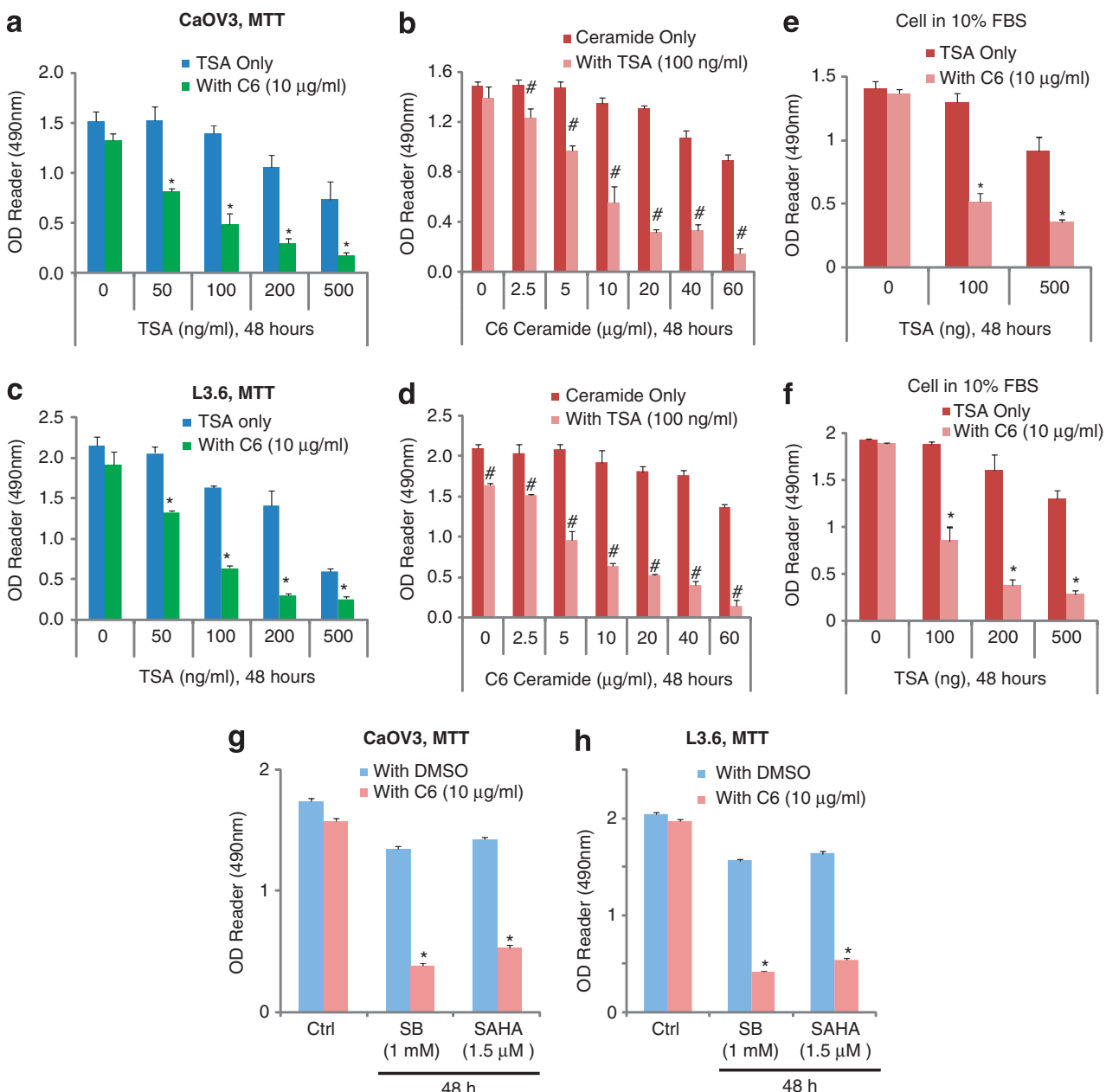

Figure 1 In vitro synergism of TSA/C6-ceramide in cancer cells death. CaOV3 ovarian cancer cell (a) and L3.6 pancreatic cancer cell (c) were treated with different doses of TSA $(0,50,100,200$ and $500 \mathrm{ng} / \mathrm{ml})$ in the presence or absence of C6-ceramide $(10 \mu \mathrm{g} / \mathrm{ml})$ for $48 \mathrm{~h}$, cell viability was detected by MTT assay as described, both cells were cultured in basic DMEM medium. CaOV3 (b) and L3.6 cells (d) were treated with varying doses of C6-ceramide $(0,2.5,5,10,20,40 \mathrm{and} 60 \mu \mathrm{g} / \mathrm{ml})$ in the presence or absence of TSA ( $100 \mathrm{ng} / \mathrm{ml}$ ) for $48 \mathrm{~h}$, cell viability was detected by MTT assay, both cells were cultured in basic DMEM medium. CaOV3 (e) and L3.6 cells (f), both maintained in $10 \%$ FBS in DMEM, were treated with combination of different dose of TSA and C6-ceramide, cell viability was detected by MTT assay. CaOV3 (g) or L3.6 cells (h) was exposed to HDACls sodium butyrate (SB, $1 \mathrm{mM}$ ) or suberoylanilide hydroxamic acid (SAHA, $1.5 \mu \mathrm{M})$, in the presence or absence of C6-ceramide $(10 \mu \mathrm{g} / \mathrm{ml})$ for $48 \mathrm{~h}$, after which the cell viability was determined by MTT assay. Data are presented as the means \pm S.D. for three independent experiments. Experiments in this figure were repeated at least three times and similar results were obtained. ${ }^{*} P<0.05$ versus same dose of TSA group without C6-ceramide treatment (ANOVA). ${ }^{\#} P<0.05$ versus same dose of C6-ceramide group without TSA treatment (ANOVA) 
Table 1 C6-ceramide enhances TSA-induced cancer cell death

\begin{tabular}{|c|c|c|c|c|c|}
\hline \multirow[b]{2}{*}{ Cell lines } & \multicolumn{3}{|c|}{ Cell death after indicated treatments (versus control) } & \multicolumn{2}{|c|}{$\mathrm{IC}_{50}$ of TSA } \\
\hline & TSA (100 ng/ml) (\%) & $\mathrm{C} 6(10 \mu \mathrm{g} / \mathrm{ml})(\%)$ & TSA+C6 (\%) & Without C6 (in ng/ml) & With C6 $(10 \mu \mathrm{g} / \mathrm{ml})$ \\
\hline $\begin{array}{l}\text { CaOV3 } \\
\text { L3.6 } \\
\text { SKOV3 } \\
\text { WM-115 }\end{array}$ & $\begin{array}{r}8.4 \pm 3.5 \\
23.8 \pm 1.1 \\
22.5 \pm 2.8 \\
23.5 \pm 3.7\end{array}$ & $\begin{array}{l}12.9 \pm 5.1 \\
10.9 \pm 3.4 \\
14.2 \pm 1.5 \\
12.9 \pm 3.0\end{array}$ & $\begin{array}{l}68.3 \pm 7.5 \\
70.1 \pm 1.4 \\
63.2 \pm 2.2 \\
61.3 \pm 6.2\end{array}$ & $\begin{array}{l}414.3 \\
314.2 \\
354.2 \\
387.9\end{array}$ & $\begin{array}{l}51.2 \mathrm{ng} / \mathrm{ml} \\
57.8 \mathrm{ng} / \mathrm{ml} \\
63.7 \mathrm{ng} / \mathrm{ml} \\
59.9 \mathrm{ng} / \mathrm{ml}\end{array}$ \\
\hline
\end{tabular}

Cancer cell lines CaOV3, L3.6, SKOV3 and WM-115 were treated with TSA $(100 \mathrm{ng} / \mathrm{ml})$ with or without C6-ceramide $(10 \mu \mathrm{g} / \mathrm{ml})$, cell viability was detected by MTT assay as shown in Figure 1, percentage of cancer cell death was calculated by reduced MTT value after treatment divided by to control MTT value. IC ${ }_{50}$ values were calculated using SPSS statistics 17.0 software (Chicago, IL, USA).

had very moderate effects on tumor cell death even at a high dose, however, combination treatment strongly induced CaOV3 and L3.6 cancer cell death (Figures 1e and f). In vitro synergism of TSA/C6-ceramide in cancer cell death was also seen in SKOV3 ovarian cancer cells (Supplementary Figures S1A and B) and WM-115 melanoma cells (Supplementary Figures S1C and D). The morphology pictures in Supplementary Figures S2A and S2B confirmed the synergistic effects of TSA/C6-ceramide on killing cancer cells. L3.6 cells cultured in 10\% FBS, treated with either TSA or C6-ceramide alone, had almost no effect on cancer cell death, whereas concurrent applications largely induced cell death (Supplementary Figure S2B). Additionally, the chemosensitization effects of C6-ceramide on other HDAClsinduced-cancer cell death were also analyzed. As shown in Figures $1 \mathrm{~g}$ and $\mathrm{h}$, C6-ceramide markedly enhanced sodium butyrate (SB) and SAHA, the other two wellcharacterized HDACls-induced cancer cell death in both CaOV3 and L3.6 cells, indicating that the chemosensitization effects of C6-ceramide on HDACls-induced cancer cell death is not limited to TSA. Interestingly, although $100 \mathrm{ng} / \mathrm{ml}$ of TSA caused a significant inhibition of cell proliferation in human hepatoma cell lines HepG2 and Huh-7, ${ }^{17}$ same concentration of TSA had almost no effect on cell proliferation in CaOV3 and L3.6 cells (Supplementary Figures S2C, D and E).

In vitro synergism of TSA/C6-ceramide in cancer cell apoptosis. We next examined the synergism between TSA and C6-ceramide in inducing cancer cell apoptosis in different cancer cell lines in vitro via varying methods, including TUNEL staining (Figure 2a), Hoechst 33342 assay (Figures $2 \mathrm{~b}$ and $\mathrm{c}$ ) and Histone-DNA ELISA assay (Figure 2d). Results show that, although C6-ceramide $(10 \mu \mathrm{g} / \mathrm{ml})$ or TSA alone had minor effect on cancer cell apoptosis, a combination of these two caused a marked increase in cancer cell apoptosis in CaOV3 (Figures 2a-d), L3.6 (Supplementary Figures S3A and S3B) and SKOV3 cells (Supplementary Figures S3C and S3D). Furthermore, the expression level of proapoptosis proteins, including Bax, cleaved-caspase 3 and -9 , was also markedly increased after TSA/C6-ceramide treatment (Figure 2e and Supplementary Figure S4A). Importantly, a combination of C6ceramide and TSA-induced cancer cell apoptosis was largely inhibited by caspase inhibitors Z-DEVDfmk (mainly against caspase-3) and Z-LEHDfmk (mainly against caspase-9) in CaOV3 (Figures $2 f$ and g) and L3.6 cells (Supplementary
Figure S4B), indicating that a combination of TSA with C6-ceramide induced a marked increase in cancer cell apoptosis in vitro. C6-ceramide also markedly increased other HDACls, including SB and SAHA-induced cancer cell apoptosis, as evidenced by Histone-DNA ELISA assay (Figure 2h).

Endogenous ceramide production is involved in TSA-induced cancer cell death. We have shown clearly that exogenous C6-ceramide markedly enhanced TSA- and other HDACIs (SB and SAHA)-induced cancer cell death and apoptosis (Figures 1, 2 and Supplementary Figures S1-S4), we then tested the possible effects of TSA on endogenous ceramide production and the effects of endogenous ceramide on TSA-induced cancer cell death. Here we found that minimally toxic concentration of TSA (200 ng/ml) administration led to an early increase (12 hours) of endogenous ceramide production in both types of cells. The ability of the acid sphingomyelinase inhibitor desipramine ${ }^{18,19}$ to diminish TSA-mediated ceramide production (Figures $3 a$ and $d$ ) and cancer cell death/apoptosis (Figures 3b, c, e and f) indicates that the toxicity of TSA involves activation of acidic sphingomyelinase and enhanced endogenous ceramide production. Interestingly, after a longer time period (48h), the intracellular ceramide level normalizes, suggesting that cancer cells may be capable of removing excess ceramide through diverse metabolic pathways. ${ }^{20,21}$ Out of different cellular ceramide metabolic pathways, ceramide glycosylation is of great importance 22,23 and might facilitate in endogenous ceramide removal from cancer cells after TSA treatment. To address this hypothesis, glycosphingolipid biosynthesis inhibitor 1-phenyl-2-decanoylamino-3-morpholino-1-propanol (PDMP) was used. ${ }^{24,25} \mathrm{We}$ find that PDMP pretreatment increased TSA-induced ceramide production and cancer cell death/apoptosis (Figure 3 ). On the basis of above-mentioned information, we proposed that TSA treatment results in shortterm intracellular ceramide accumulation (12 h), which, as a result of metabolic (glycosylation) removal, does not result in evident increase of cancer cell death. However, co-treatment with the ceramide glycosylation inhibitor PDMP or by directly adding exogenous cell-permeable C6-ceramide leads to a very pronounced increase in ceramide levels and marked increase in cell death (Figures 1 and 2).

PI3K/AKT inhibition sensitizes cancer cell to TSA-induced cell death/apoptosis in vitro. We then examined whether PI3K/AKT inhibition affected TSA-induced cancer cell death 

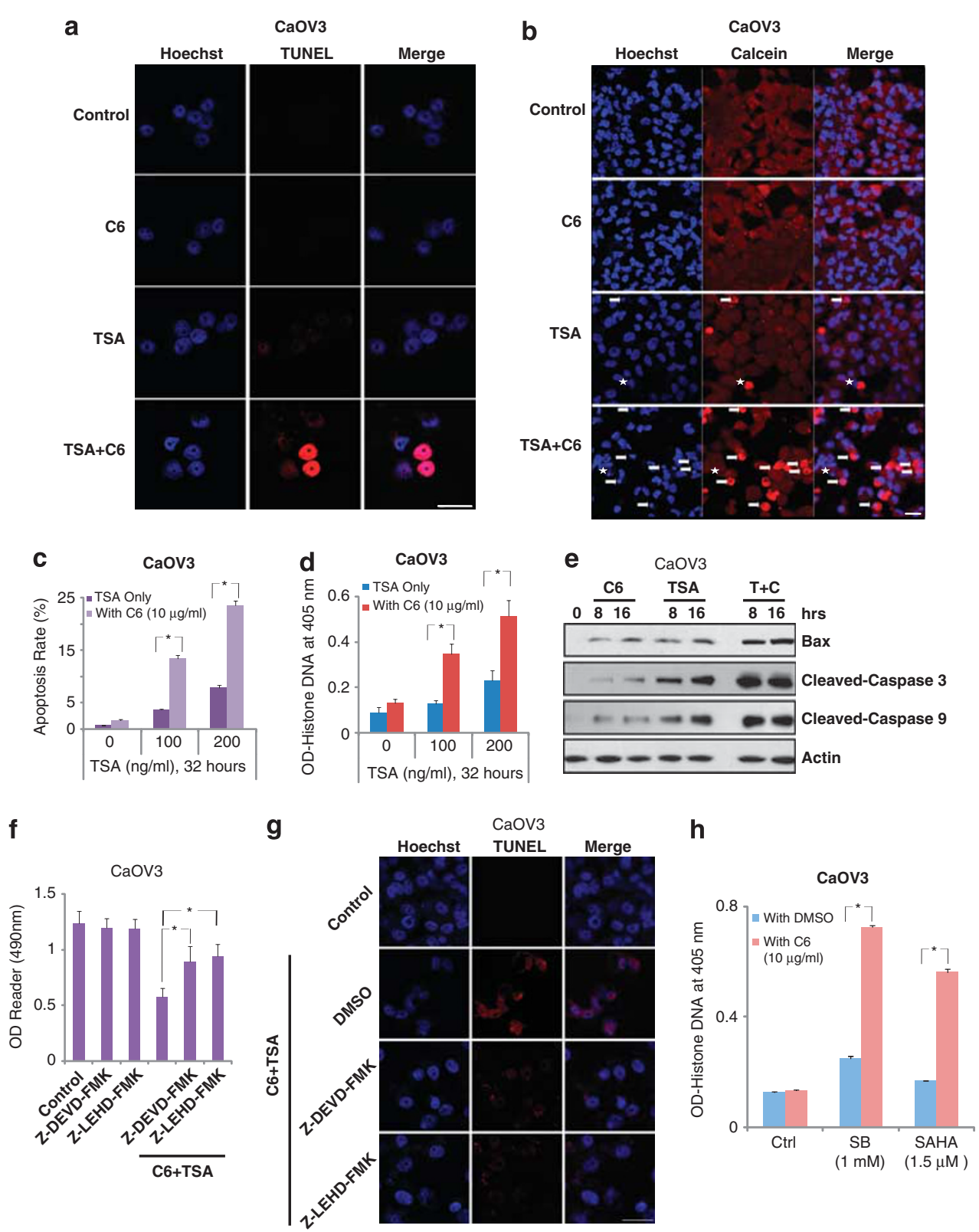

Figure 2 In vitro synergism between TSA and C6-ceramide in inducing cancer cell apoptosis. The apoptosis of CaOV3 cells with indicated treatment (control, $100 \mathrm{ng} / \mathrm{ml}$ of TSA, $10 \mu \mathrm{g} / \mathrm{ml}$ of C6-ceramdie and TSA plus C6-ceramide) for $32 \mathrm{~h}$ was detected by different methods including TUNEL assay (a), Hoechst 33342 assay (b), Histone DNA apoptosis ELISA assay (d). For each Hoechst experiment, at least 200 cells in 10 random scope fields were counted for apoptotic rate (c). CaOV 3 cells were treated with $100 \mathrm{ng} / \mathrm{ml}$ of TSA in the presence or absence of $10 \mu \mathrm{g} / \mathrm{ml}$ of C6-ceramide for 8 and $16 \mathrm{~h}$, the expression level of Bax, cleaved-caspase $3,-9$ and $\beta$-actin were detected by western blot (e). CaOV3 cells were pretreated with caspase inhibitors Z-DEVDfmk $(50 \mu \mathrm{M})$ or Z-LEHDfmk $(50 \mu \mathrm{M})$ for $2 \mathrm{~h}$, followed by TSA (100 ng/ml) plus C6-ceramide $(10 \mu \mathrm{g} / \mathrm{ml})$ treatment; cell death was detected by MTT assay (f) at $48 \mathrm{~h}$ after treatment, and CaOV3 cells apoptosis was detected by TUNEL assay $36 \mathrm{~h}$ after treatment $(\mathbf{g})$. $\mathrm{CaOV} 3(\mathrm{~h})$ were exposed to HDACls sodium butyrate $(\mathrm{SB}, 1 \mathrm{mM})$ or suberoylanilide hydroxamic acid (SAHA, $1.5 \mu \mathrm{M})$, in the presence or absence of C6-ceramide (10 $\mu \mathrm{g} / \mathrm{ml})$ for $36 \mathrm{~h}$, cell apoptosis was detected by Histone DNA apoptosis ELISA assay. Data are presented as the mean \pm S.D. for three independent experiments. Experiments in this figure were repeated at least three times and similar results were obtained. Bar $=10 \mu \mathrm{m} .{ }^{*} P<0.05$ versus that indicated in the figure (ANOVA)

in vitro. First, shRNAs specific to AKT1 and AKT2 were used to generate AKT1/2 double-knockdown stable L3.6 cancer cells (Figure 4a). AKT1/2 shRNA-knockdown stable cells were highly sensitive to TSA compared with control shRNAtreated cells (Figure 4b). Further, AKT inhibitor X (AKTi), a commercial available specific inhibitor of AKT, largely enhanced TSA-induced cell death in L3.6 cells (Figures 4C and d). AKT1/2-knockout mouse embryonic fibroblasts
(MEFs) (Supplementary Figure S5) were highly sensitive to TSA-induced cell death (Figure 4e) and apoptosis (Figure 4f). These results indicate that PI3K/AKT activation is a major factor contributing to TSA resistance.

In vitro synergism of TSA/C6-ceramide in AKT/mTOR inhibition. As we have clearly shown the in vitro synergism between TSA and C6-ceramide in inducing cancer cell death/ 

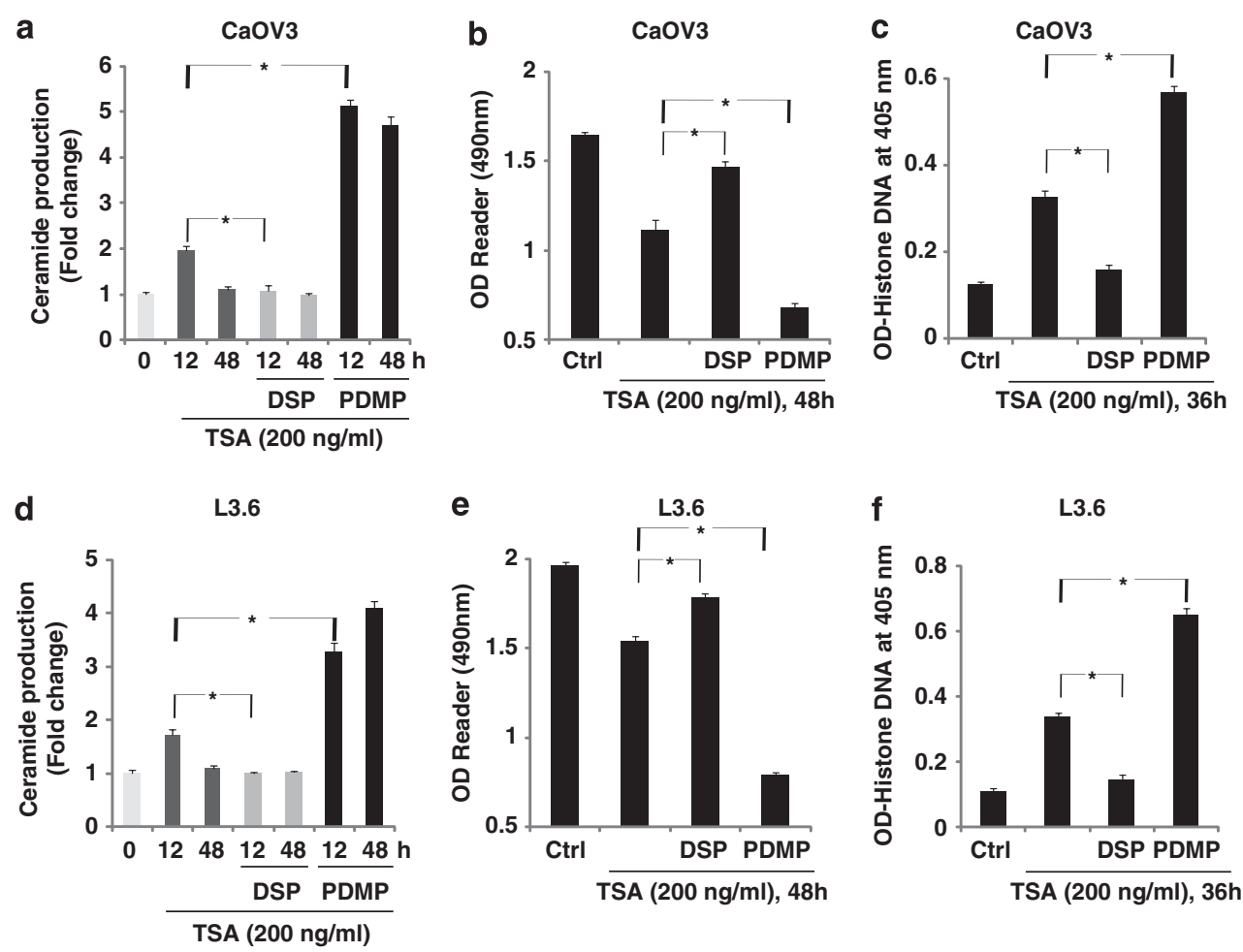

Figure 3 Endogenous ceramide production is involved in TSA-induced cancer cell death. CaOV3 (a-c) or L3.6 (d-f) cells were pretreated with the glycosphingolipid biosynthesis inhibitor 1-phenyl-2-decanoylamino-3-morpholino-1-propanol (PDMP, $10 \mu \mathrm{M}$ ) or the acid sphingomyelinase inhibitor desipramine (DSP, $30 \mu \mathrm{M}$ ) for $2 \mathrm{~h}$, followed by $200 \mathrm{ng} / \mathrm{ml}$ of TSA treatment, endogenous cellular ceramide production (indicated as fold change) was detected by the methods as described above after $12 \mathrm{or} 48 \mathrm{~h}$ (a and d), cell death and apoptosis were detected by MTT assay (b and $\mathbf{e}, 48 \mathrm{~h}$ after TSA treatment) and Histone DNA ELISA assay (c and $\mathbf{f}, 36 \mathrm{~h}$ after TSA treatment) independently. Data are presented as the mean \pm S.D. for three independent experiments. Experiments in this figure were repeated at least three times and similar results were obtained. ${ }^{*} P<0.05$ versus that indicated in the figure (ANOVA)

apoptosis (Figures 1 and 2) and AKT activation serves as a major resistant factor against TSA-induced cell death (Figure 4), we next tested the possible effects of TSA plus C6-ceramide on AKT and downstream mTOR activation. C6-ceramide or TSA alone had moderate effect on AKT/mTOR inhibition, whereas a combination of these two drugs induced a large inhibition of AKT/mTOR activation in both cells (Figures $5 a$ and b, Supplementary Figure S6). Previous studies have shown that C6-ceramide activates PP1, a serine/threonine phosphatase, which is involved in AKT dephosphorylation and inhibition. ${ }^{26-28}$ Interestingly, recent studies also indicated that TSA and other HDACls induce PP1 association with AKT, leading to AKT dephosphorylation. ${ }^{8}$ Here, we confirmed that either C6-ceramide or TSA alone induced moderate association between PP1 and AKT, whereas a combination of these two drugs leads to their marked increase in association in both $\mathrm{CaOV}_{3}$ (Figure 5c) and L3.6 cells (Figure 5d), as evidenced by coimmunoprecipitation assay. It might be the key mechanism to explain the synergism between TSA and C6-ceramide in causing AKT/mTOR inhibition. As previous studies have established that $\mathrm{C6}$-ceramide activates two important phosphatases $\mathrm{PP}^{29}$ and $2 \mathrm{~A}$ class of serine/threonine phosphatases (PP2A), ${ }^{26-28}$ we next tested the relative contribution of these two on TSA/C6-ceramide-mediated AKT inhibition. As shown in Figures $5 e$ and $\mathrm{f}$, PP1-specific inhibitor PP1 i2 but not PP2A-specific inhibitor Cantharidin reversed TSA/C6-ceramide-induced AKT inhibition, indicating that PP1 rather than PP2A mediates AKT inhibition by TSA/C6-ceramide treatment. Importantly, as shown in Figures $5 \mathrm{~g}$ and $\mathrm{h}$, a combination of these two drugs led to a marked increase of PP1 activity compared with either C6-ceramide or TSA treatment alone in both cell types (Figures $5 \mathrm{~g}$ and $\mathrm{h}$ ). Additionally, TSA had almost no effect on PP2A activity either alone or with C6-ceramide (Data not shown). To further confirm the requirements of PP1/ HDAC6 in TSA- and C6-ceramide-induced AKT inhibition, specific siRNA knockdown were used. As shown in Figures $5 i$ and $j$, although knockdown of either PP1 or HDAC6 alone partially inhibited TSA/C6-ceramide induced AKT inhibition, knockdown of both proteins almost completely blocked its effects (Figure 5k). To further confirm the requirement of PP1 in the deactivation of AKT by TSA/C6-ceramide, a loss-of-function dominantnegative myc-D95N PP1 was used. As shown in Figure 5I, TSA plus C6-ceramide-induced AKT/mTOR inhibition was reduced in myc-PP1 mutant L3.6 cells. On the basis of this information, we suggested that combined treatment of TSA/ C6-ceramide synergistically disrupts HDAC6/PP1/tubulin complex, leading to the release of PP1, which is then activated by C6-ceramide. Activated PP1 then associates with AKT, resulting in AKT dephosphorylation and inhibition, which might be the key mechanism of synergism between C6-ceramide and TSA. 
a L3.6 Cell, MTT assay

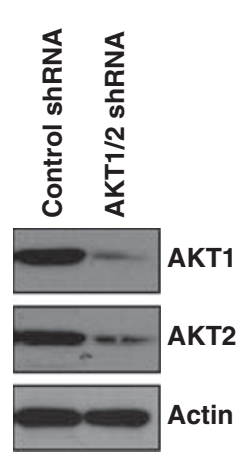

b

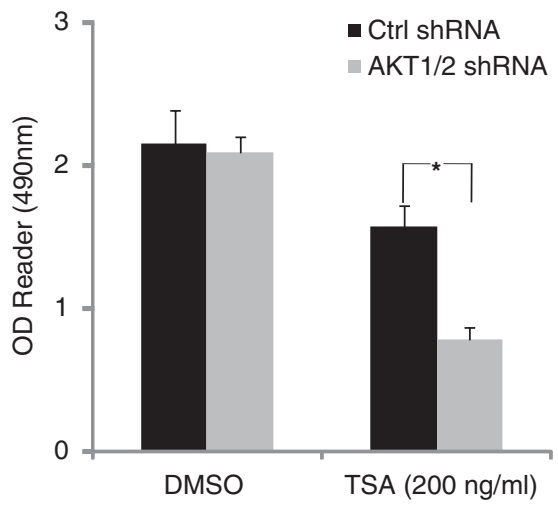

d

L3.6 Cell, MTT assay

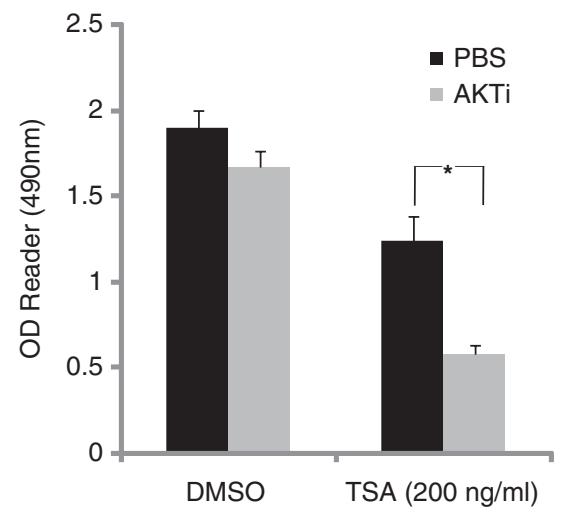

L3.6 Cell, MTT assay

- Ctrl shRNA

MEFs, MTT assay

e

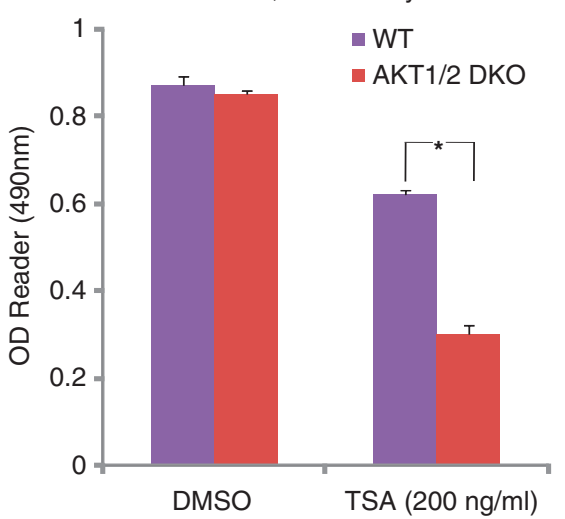

c L3.6 Cell, MTT assay

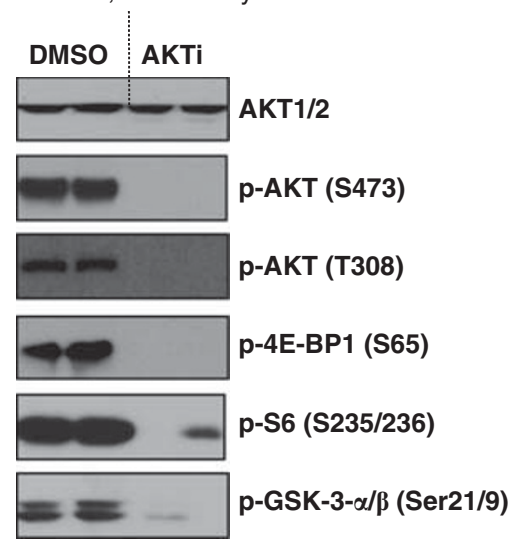

f

MEFs, apoptosis assay

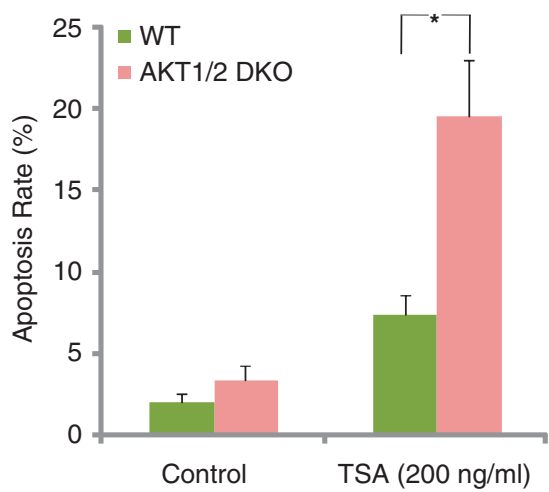

Figure 4 PI3K/AKT inhibition sensitizes cancer cell to TSA induced cell death/apoptosis in vitro. L3.6 was transfected with either control or AKT1/2 shRNA and cultured for $48 \mathrm{~h}$, successfully transfected cells were selected by puromycin $(1 \mu \mathrm{M})$. AKT1/2 expression levels were detected in the stable cells (a). Control cells and AKT1/2 shRNA stable L3.6 cells were then treated with $200 \mathrm{ng} / \mathrm{ml}$ of TSA and cell viability was detected by MTT assay (b). L3.6 cell was either left untreated or treated with AKTi (10 $\mu \mathrm{M})$ for $2 \mathrm{~h}$; AKT and downstream mTOR activation were detected by western blot using commercially available antibodies as indicated (c). L3.6 cell was pretreated with $\mathrm{AKTi}(10 \mu \mathrm{M})$ for $2 \mathrm{~h}$, followed by $200 \mathrm{ng} / \mathrm{ml}$ of TSA treatment; cell death was detected by MTT assay (d). WT and AKT1/2 double-knockout MEFs were treated with $200 \mathrm{ng} / \mathrm{ml}$ of TSA for $72 \mathrm{~h}$, the cell viability was detected by MTT assay (e), cell apoptosis was detected by Hoechst staining at $36 \mathrm{~h}$ after TSA treatment and apoptosis rate was quantified in (f). Data are presented as the mean \pm S.D. for three independent experiments. Experiments in this figure were repeated at least three times and similar results were obtained. ${ }^{*} P<0.05$ versus that indicated in the figure (ANOVA)

In vitro synergism of TSA/C6-ceramide in $\alpha$-tubulin acetylation in cancer cell lines. Previous studies have shown that TSA disrupts HDAC6/ $\alpha$-tubulin complex, causing $\alpha$-tubulin acetylation and microtubulin stabilization. ${ }^{30}$ Compared with controls, thicker and denser microtubule bundles were evident in TSA-treated cells, which contributes to cancer cell apoptosis. ${ }^{30}$ We tested the possible effects of TSA/C6-ceramide on tubulin acetylation. As shown in Figures $6 a$ and $b$, although C6-ceramide or TSA alone had moderate effect in $\alpha$-tubulin acetylation, a combination of these two drugs induced a large enhancement of $\alpha$-tubulin acetylation in both cells. Furthermore, combination treatment induced strong disruption of HDAC6/ $\alpha$-tubulin complex, which might lead to $\alpha$-tubulin acetylation in both cells (Figures $6 c-f$ ). $\alpha$-Tubulin acetylation is one of the consequences of microtubule stability, resulting in cell cycle arrest and apoptosis. ${ }^{30-32}$ Specific siRNA-knockdown cells were used to confirm the requirements of PP1/HDAC6 in TSA- and C6-ceramide-induced $\alpha$-tubulin acetylation. HDAC6 silencing, which produced an increase in tubulin acetylation at basic level (non-treatment) inhibited TSA plus C6-ceramide-induced enhancement of tubulin acetylation (Figure 6g), PP1 siRNA also inhibited, in relatively lower level, TSA plus C6-ceramide-induced $\alpha$-tubulin acetylation (Figure 6h). Knockdown of both proteins almost reversed the effects (Figure 6i). On the basis of above-mentioned information, we propose that C6-ceramide and TSA synergistically cause the disruption HDAC6/ $\alpha$-tubulin complex, leading to $\alpha$-tubulin hyperacetylation and eventually cancer cell death, another potentially important mechanism to explain the synergism.

C6-ceramide enhances the anti-tumoral efficacy of TSA in vivo. Two human tumor mice xenograft models were used for testing the efficacy of the combination treatment. In both L3.6 and CaOV3 tumor models, the groups that 
a

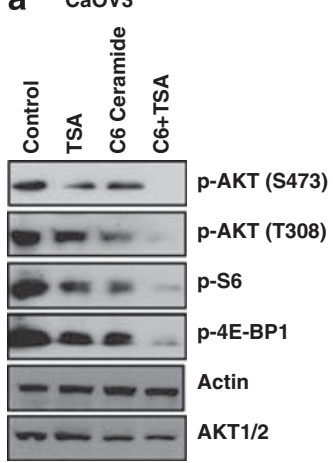

C

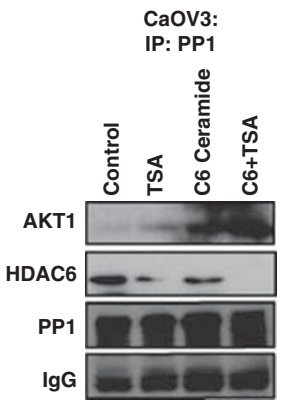

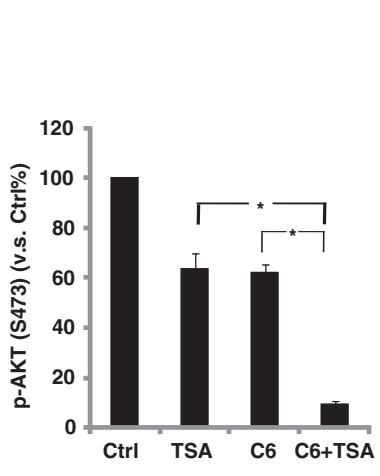

d b

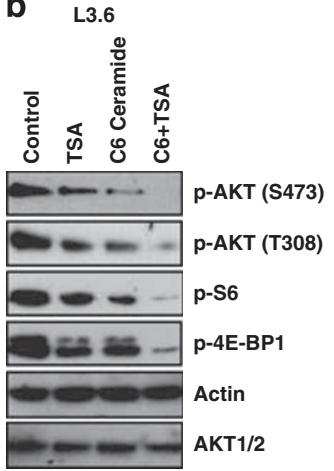

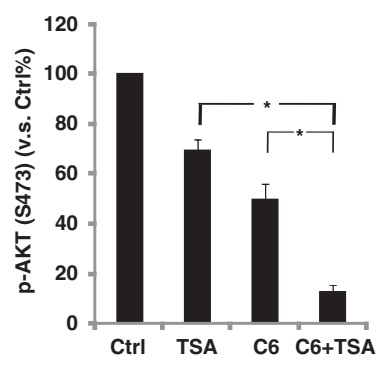

f

CaOv3:

L3.6:

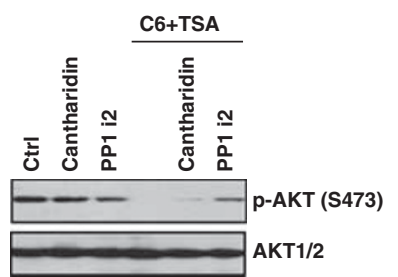

g

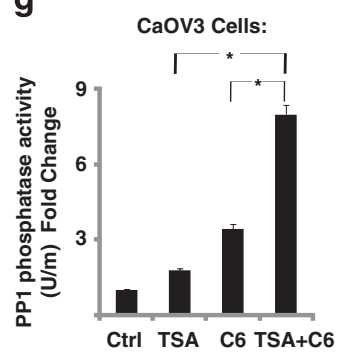

h

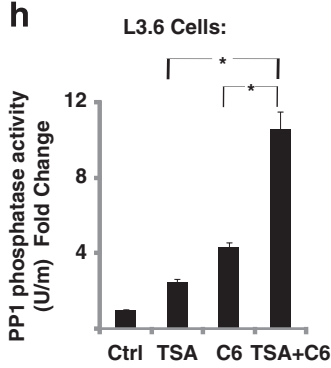

k

L3.6 Cells scramble pp1+HDAC6 siRNAs

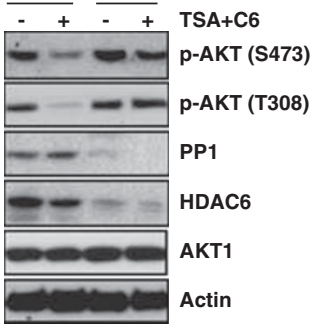

L3.6 Cells

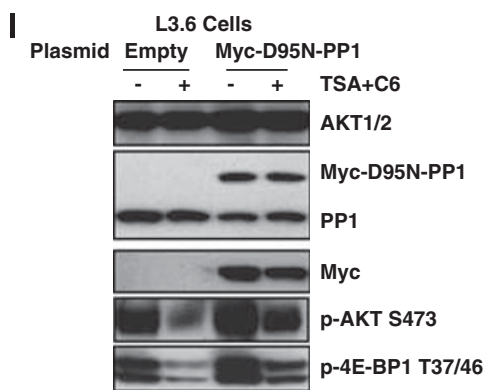

Figure 5 In vitro synergism of TSA/C6-ceramide in AKT/mTOR inhibition. CaOV3 or L3.6 cells were either left untreated or treated with indicated treatment (100 ng/ml of TSA, $10 \mu \mathrm{g} / \mathrm{ml}$ of C6-ceramide and TSA plus C6-ceramide) for $12 \mathrm{~h}$; AKT and downstream mTOR activation were detected by western blot assay by using commercially available antibodies ( $\mathbf{a}$ and $\mathbf{b})$. CaOV3 or L3.6 cells were either left untreated or treated with indicated treatment $(100 \mathrm{ng} / \mathrm{ml}$ of TSA, $10 \mu \mathrm{g} / \mathrm{ml}$ of C6-ceramide and TSA plus C6-ceramide) for $2 \mathrm{~h}$, the association between PP1/HDAC6/AKT1 were detected by immunoprecipitation (IP) assay as described (c and d). CaOV3 or L3.6 cells were pretreated with PP1-specific inhibitor PP1 i2 (5 $\mu \mathrm{M})$ or PP2A-specific inhibitor Cantharidin $(5 \mu \mathrm{M})$ for $1 \mathrm{~h}$, followed by TSA/C6-ceramide treatment for another $12 \mathrm{~h}$, p-AKT (Ser 473$)$ and AKT were detected by western blot (e and f). CaOV3 or L3.6 cells were either left untreated or treated with indicated treatment $(100 \mathrm{ng} / \mathrm{ml} \mathrm{of} \mathrm{TSA,} 10 \mu \mathrm{g} / \mathrm{ml}$ of C6-ceramdie and TSA plus C6-ceramide) for $2 \mathrm{~h}$, PP1 activity was detected as described ( $\mathbf{g}$ and $\mathbf{h}$ ). L3.6 cells were transfected with control siRNA (scramble, $250 \mathrm{nM}$ ), PP1 siRNA (250 nM), HDAC6 siRNA (250 nM), PP1 + HDAC6 (250 nM each) for $72 \mathrm{~h}$ (to reach maximum transfection efficiency) using RNAi methods as aforementioned, expression level of PP1 and HDAC6 were measured using western blot. Successfully knockdown cells were used for further experiment. PP1/HDAC single (i and j) or double (k) knockdown L3.6 cells were treated with TSA $(100 \mathrm{ng} / \mathrm{ml})$ plus C6-ceramide $(10 \mu \mathrm{g} / \mathrm{ml})$ for indicated time points; p-AKT, actin, PP1 and HDAC6 were detected by western blot. (I) L3.6 cells transfected with empty vector or Myc-D95N-PP1 plasmids (1 $\mu \mathrm{g} /$ well, described in materials and methods) were treated with TSA (100 ng/ml) plus C6-ceramide (10 $\mu \mathrm{g} / \mathrm{ml})$ for $24 \mathrm{~h}$ and AKT/mTOR activation was detected using specific antibodies. Data are presented as the mean \pm S.D. for three independent experiments. ${ }^{*} P<0.05$ versus that indicated in the figure (ANOVA). All experiments were repeated at least three times and similar results were obtained 
a

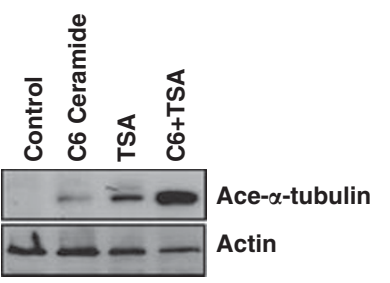

b $\quad$ L3.6

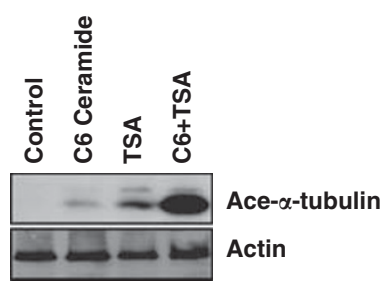

e

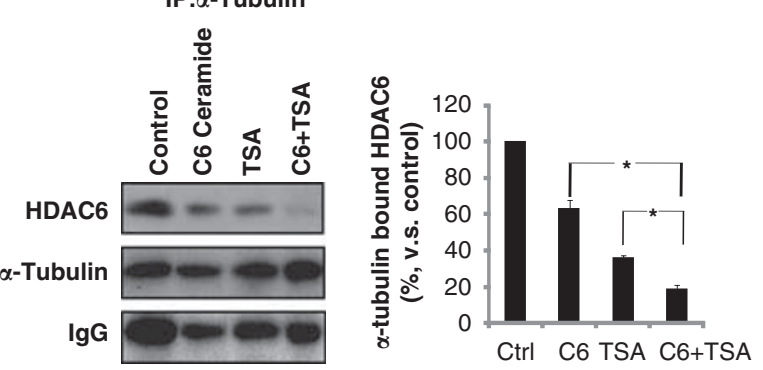

9

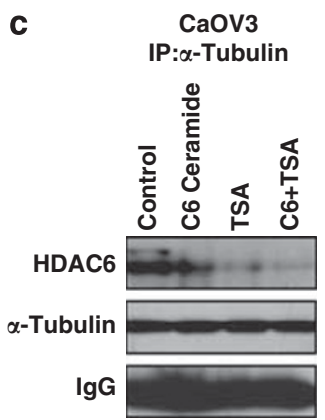

d

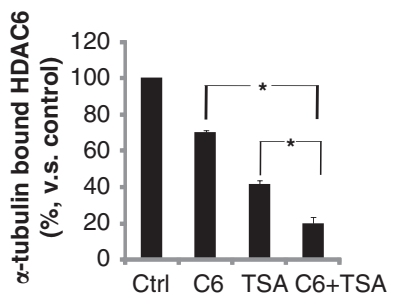

h

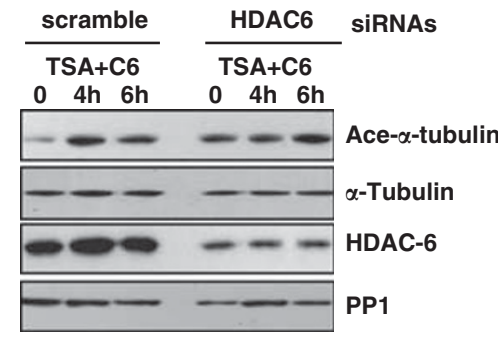

j

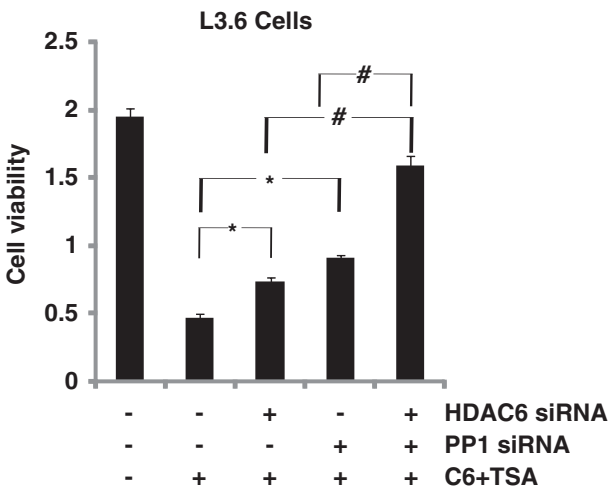

L3.6 Cells

\begin{tabular}{|c|c|c|}
\hline scramble & PP1 & siRNAs \\
\hline $\mathrm{TSA}+\mathrm{C} 6$ & TSA+C6 & \\
\hline $0 \quad 4 h \quad 6 h$ & $0 \quad 4 h \quad 6 h$ & \\
\hline 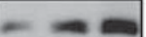 & $--\infty$ & Ace- $\alpha$-tubulin \\
\hline$-\infty$ & $-\infty$ & $\alpha$-Tubulin \\
\hline
\end{tabular}

i $\quad$ L3.6 Cells scramble pp1+HDAC6 siRNAs
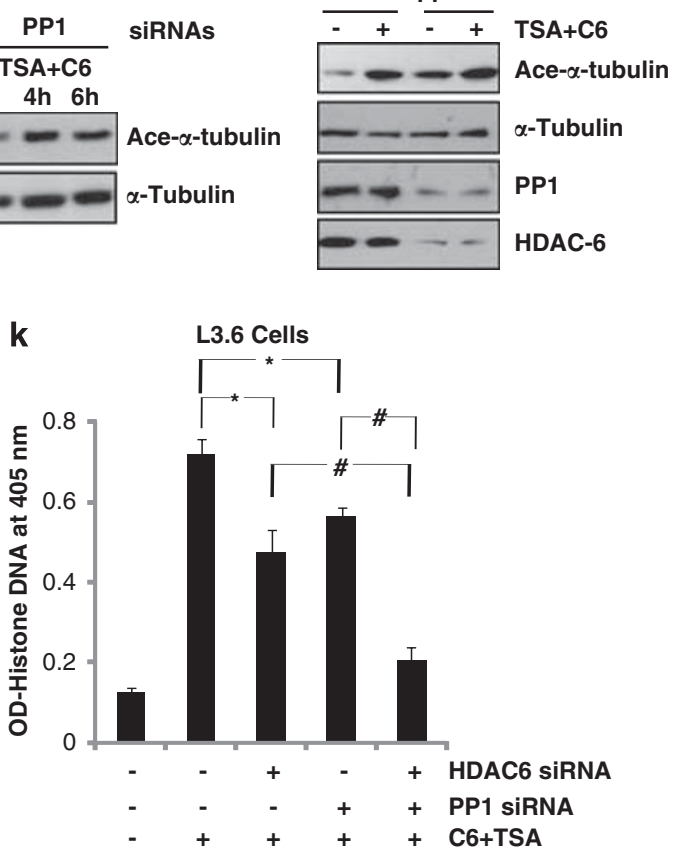

Figure 6 In vitro synergism of TSA/C6-ceramide in $\alpha$-tubulin acetylation in cancer cell lines. CaOV3 or L3.6 cells were either left untreated or treated with indicated treatment ( $100 \mathrm{ng} / \mathrm{ml}$ of TSA, $10 \mu \mathrm{g} / \mathrm{ml}$ of C6-ceramide and TSA plus C6-ceramide) for $4 \mathrm{~h}, \alpha$-tubulin acetylation were detected by western blot assay by using commercially available antibodies ( $\mathbf{a}$ and $\mathbf{b})$ ). $\mathrm{CaOV} 3$ or $\mathrm{L} 3.6$ cells were either left untreated or treated as indicated ( $100 \mathrm{ng} / \mathrm{ml}$ of TSA, $10 \mu \mathrm{g} / \mathrm{ml}$ of C6-ceramide and TSA plus C6-ceramide) for $2 \mathrm{~h}$, the association between HDAC6/ $\alpha$-tubulin were detected by immunoprecipitation assay as described (c-f). PP1 knockdown, HDAC6 knockdown, PP1/HDAC6 both knockdown L3.6 cells were treated with TSA $(100 \mathrm{ng} / \mathrm{ml})$ plus C6-ceramide $(10 \mu \mathrm{g} / \mathrm{ml})$ for indicated time points and ace- $\alpha$-tubulin and $\alpha$-tubulin were detected by western blot $(\mathbf{g}-\mathbf{i})$. The effects of PP1/HDAC siRNA knockdown (either alone or combined) on TSA (100 ng/ml) plus C6-ceramide $(10 \mu \mathrm{g} / \mathrm{ml})$ induced-L3.6 cell death/apoptosis were detected $48 \mathrm{~h}$ after treatment using MTT (j) and Histone-DNA ELISA assays (k) as described above. The values in the figures are expressed as the means \pm S.D. All experiments were repeated at least three times and similar results were obtained. ${ }^{*} P<0.05$ and ${ }^{\#} P<0.05$ versus that indicated in the figure (ANOVA)

received treatment with either TSA or C6-ceramide as single agents showed moderately inhibited tumor growth, whereas the group that received concurrent treatment showed a great inhibition in tumor growth (enhanced survival rate and reduced tumor size) (Figures $7 a-d)$. We wondered whether the in vivo synergism between TSA and C6-ceramide might be in part related to their effects on tubulin acetylation and AKT inhibition, as observed in our in vitro studies. Western blot analysis was performed on total proteins extracted from the tumor tissues of mouse xenografts treated with solvent, 

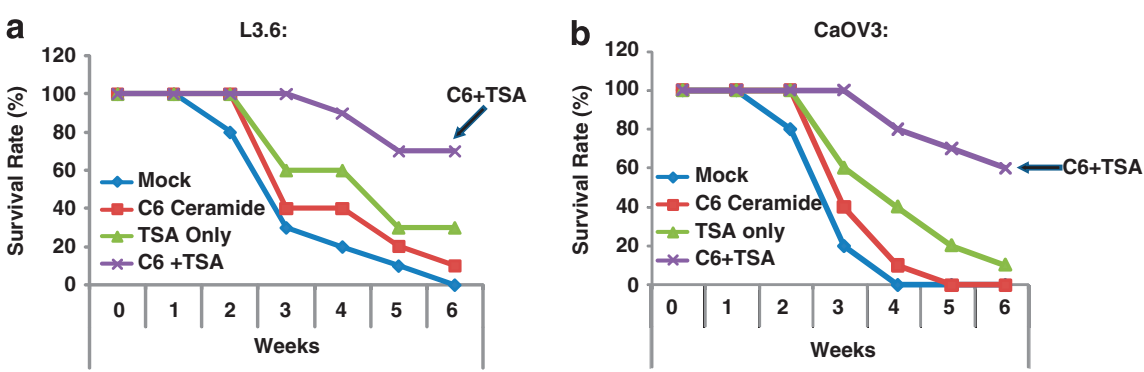

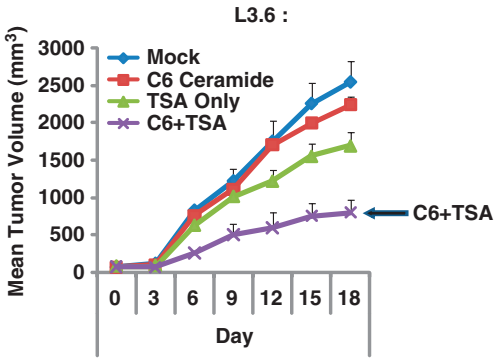

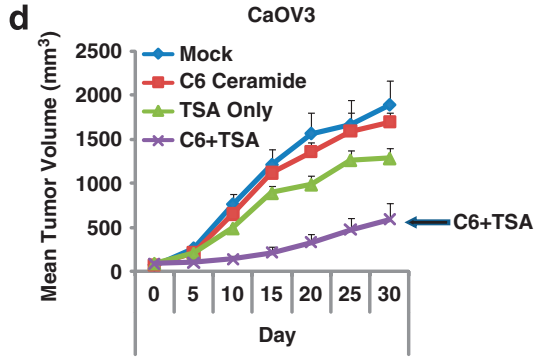

e

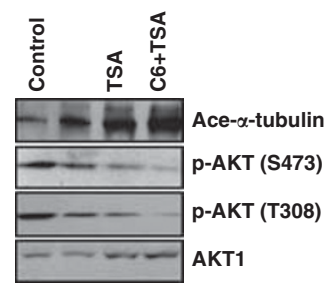

f

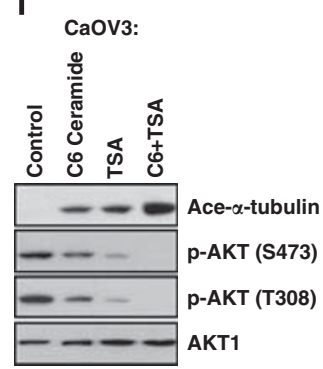

g

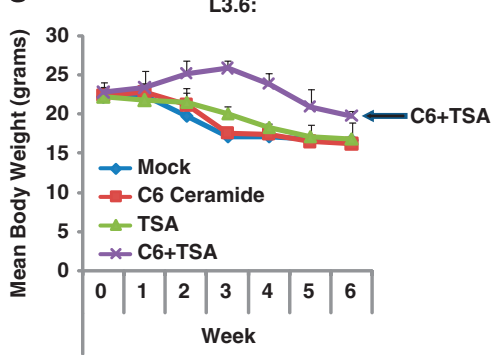

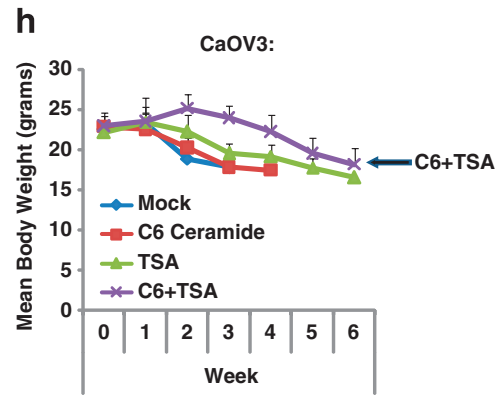

Figure 7 C6-ceramide enhances the anti-tumoral efficacy of TSA in vivo. Mice survival and tumor growth were compared with L3.6 ( $n=10 /$ group) (a and c) and CaOV3 ( $n=10$ /group) models ( $\mathbf{b}$ and $\mathbf{d}$ ). In both models, only groups that received both TSA plus $\mathrm{C6}$-ceramide treatment showed significantly smaller tumor volumes and enhanced mice survival as compared with the mock treatment (control) group, and the group that received single treatment (TSA or C6-ceramide) showed very limited effect in tumor volume/mice survival. AKT activation and tubulin acetylation were analyzed. In both models, at 4 weeks after drug treatment (mock, TSA, C6-ceramide, combination), tumor xenograft were freshly removed, solubilized and lysed using lysis buffer, followed by western blot detecting AKT phosphorylation and tubulin acetylation (e and f). The effects of different treatments (mock, TSA, C6-ceramide, C6-ceramide plus TSA) on body weight of mice in the xenograft models were demonstrated in $\mathbf{g}$ (L3.6 cell model) and $\mathbf{h}$ (CaOV3 model). All experiments were repeated at least three times and similar results were obtained

TSA, C6-ceramide, or TSA and C6-ceramide. Although single-agent treatment with either TSA or C6-ceramide alone had moderate effect on tubulin acetylation or AKT inhibition, combined treatment led to a marked increase in tubulin acetylation and a decrease in AKT activation (Figures $7 e$ and $f$ ). The effect of different treatments (control, TSA, C6-ceramide, TSA plus C6-ceramide) on body weight of mice in the xenograft models were demonstrated in Figures $6 \mathrm{~g}$ and $\mathrm{h}$. These results are consistent with our in vitro experiments and suggest that tubulin acetylation/ microtubule stabilization and AKT inhibition might have an important role in the effectiveness of the TSA/C6-ceramide combination.

\section{Discussion}

In this study, we defined the anti-tumor activity of TSA and other HDACls (SB and SAHA) in combination with C6-ceramide in CaOV3 and L3.6 cancer cells both in vitro and in vivo. Moderate cancer death and apoptosis were seen in CaOV3 cells and L3.6 cells, following treatment with C6-ceramide or TSA (and other HDACls) alone, whereas simultaneous treatment with TSA/HDACls and C6-ceramide caused synergistic effects, and a marked increase in cancer cell death and apoptosis (Figures 1 and 2). We provided evidence to support that treatment with TSA resulted in an early ceramide accumulation (12 h), which, as a result of metabolic (glycosylation) removal, might not result in a big increase of cancer cell death. However, co-treatment with the ceramide glycosylation inhibitor or directly adding exogenous cell-permeable C6-ceramide led to a very pronounced increase in ceramide levels and marked increase in cell death (Figure 3). We suggested that agents that interfere with ceramide metabolic pathways (for example, PDMP) might sensitize cancer cells to TSA and possibly other HDAClsinduced cancer cell death. Activation of AKT is a major factor contributing to resistance against TSA-induced cancer cell death, whereas AKT inhibition sensitized cancer cells to TSA-induced cell death/apoptosis (Figure 4). We provide evidence to support the model that combined treatment 
with TSA/C6-ceramide synergistically disrupts HDAC6/PP1/ tubulin complex, leading to the release of PP1, which is then activated by C6-ceramide. Subsequently, activated PP1 then associates with AKT, leading to AKT dephosphorylation and inhibition (Figure 5). C6-ceramide and TSA synergistically cause the disruption HDAC6/ $\alpha$-tubulin complex, leading to $\alpha$-tubulin hyperacetylation and eventually cancer cell death (Figure 6). Importantly, the anti-tumor activity of TSA in combination with C6-ceramide was also seen in in vivo human tumor mice xenograft models. The groups that received treatment with either TSA or C6-ceramide, as single agents, showed moderate inhibition of tumor growth, whereas the group that received the concurrent treatment showed a significant inhibition in tumor growth (Figure 7). In conclusion, we discovered the synergistic anti-tumor effects of TSA plus C6-ceramide, both in vitro and in vivo.

Recent studies have indicated the relationship between TSA and AKT dephosphorylation/inhibition. Those studies confirmed the existence of cellular HDACs (1 and 6) PP1 complex, and showed that this complex was disrupted by the treatment of cells with TSA. This caused the release of PP1 from the nuclear PP1/HDACs complex and accounted for the dephosphorylation of AKT, ${ }^{8,33}$ which serves as an important mechanism to explain the anti-tumor effects of TSA. Here, we suggest that released PP1 is further activated by C6-ceramide, which causes further AKT dephosphorylation and inhibition (Figure 5). Several candidate ceramide-regulated enzymes, including ceramide-activated protein phosphatase (CAPP) have been identified. CAPP was identified as a member of the PP2A ${ }^{26-28}$ and PP1. ${ }^{29}$ Now, it is well established that short-chain ceramide including C6-ceramide activates PP1 and PP2A. The specificity for CAPP activation in vitro closely resembled the specificity for various cellular activities of ceramide. ${ }^{29}$ PP1 and PP2A comprises more than $90 \%$ of serine/threonine phosphatase activity in mammalian cells. Both PP1 and PP2A can be activated by C6-ceramide; here, we found that activation of PP1, but not PP2A, is important for AKT dephosphorylation by C6-ceramide/TSA treatment. As PP1 inhibitor, but not PP2A inhibitor, reverses AKT inhibition by C6-ceramide/TSA treatment, further C6-ceramide/TSA treatment synergistically enhances PP1 activity, and C6-ceramide/TSA-induced AKT inhibition is inhibited by PP1 siRNA knockdown and by introducing a loss-of-function PP1 (dominant negative) to L3.6 cells (Figure 5).

The HDAC6 catalytic domain binds $\alpha$ - and $\beta$-tubulin, two major components of cytoplasmic microtubules, and catalyzes the deacetylation of $\alpha$-tubulin. ${ }^{34-36}$ Recent studies observed a small fraction of the total cellular $\alpha$-tubulin in the HDAC6/PP1 complex in control cells. Most importantly, treatment with the broad specificity HDAC inhibitor TSA promoted the disassembly of the HDAC6/PP1 complex and greatly enhanced the acetylation of $\alpha$-tubulin that was associated with the remaining PP1 complex. ${ }^{34-36}$ Because $\alpha$-tubulin acetylation increases following microtubule assembly, it is suggested that PP1 facilitates the recruitment of HDAC6 to modulate microtubule dynamics. In this regard, the prevailing evidence implicates HDAC6 in destabilizing microtubules, whereas inhibition of HDAC6 induces $\alpha$-tubulin acetylation and microtubule stabilization. Interestingly, PP1, which is also recruited to microtubules by the microtubuleassociated protein (MAP) Tau, dephosphorylates Tau and other MAPs to stabilize microtubules. ${ }^{37}$ On the basis of these results, we suggest that TSA administration disrupts HDACs/ PP1/tubulin complex, leading PP1-bound tubulin acetylation and stabilization, which is involved in disruption of cell division and induction of cell apoptosis. Activation of PP1 by C6-ceramide appears to enhance the acetylation of tubulin, probably by further disrupting HDAC6/tubulin complex (Figure 6).

Besides promoting cancer cell apoptosis, another important anti-tumor characteristic of ceramide is anti-cancer cell invasion. ${ }^{38,39}$ Interestingly, though the present study convincingly demonstrated that co-administration TSA and exogenous C6-ceramide resulted in a striking increase in cancer cell apoptosis, previous study has shown that TSA counteracted C2-ceramide's (another short-chain ceramide) inhibitory effects on tumor cell invasion in vitro. ${ }^{39}$ This counteraction effect, resulting from such combination could, however, affect the effectiveness of current combination approaches (ceramide plus HDACls), but more in vivo experiments might be needed to test this hypothesis. In conclusion, TSA in combination with C6-ceramide exert synergistic anti-tumor effects via AKT dephosphorylation (inhibition) and $\alpha$-tubulin acetylation, both in vitro and in vivo.

\section{Materials and Methods}

Chemicals and reagents. C6-ceramide was purchased from Avanti (Alabaster, AL, USA AB, CN: 860506P); TSA, AKT inhibitor X (AKTi) and Rapamycin were purchased from CalbioChem (San Diego, CA, USA). AKT1/2, Tubulin, HDAC6, PP1, goat anti-rabbit IgG-HRP and goat anti-mouse IgG-HRP antibody were purchased from Santa Cruz Biotechnology (Santa Cruz, CA, USA). PP2A-specific inhibitor Cantharidin, PDMP, desipramine, SB, and monoclonal mouse anti- $\beta$-actin were obtained from Sigma (St. Louis, MO, USA). PP1-specific inhibitor PP1 I2 was purchased from B\&D Bioscience (Franklin Lakes, NJ, USA). P-AKT (Ser473), p-AKT (Thr308), p-4E-BP1 (Ser65), p-S6 (S235/236), cleavedcaspase 3 and -9 antibodies were purchased from Cell Signaling Technology (Beverly, MA, USA). SAHA was purchased from Biomol International (Plymouth Meeting, PA, USA).

Cell culture. Ovarian cancer cell line $\mathrm{CaOV} 3, \mathrm{SKOV} 3$ cells, pancreatic cancer cell line L3.6 cells, melanoma cell line WM-115 cells, hepatoma cells HepG2 and Huh-7 (purchased from Shanghai Maisha Biological Technology, Shanghai, China), AKT wildtype and AKT1/2 double-knockout MEFs were maintained in a DMEM medium (Sigma), supplemented with a 10\% FBS (Invitrogen, Carlsbad, CA, USA), penicillin/streptomycin (1:100, Sigma) and $4 \mathrm{mM}$ L-glutamine (Sigma) in a $\mathrm{CO}_{2}$ incubator at $37^{\circ} \mathrm{C}$.

Cell viability and the percentage of apoptotic cells assay. Cell viability was measured by the MTT method. Cells with indicated treatments were incubated for 20 min with $5 \mu \mathrm{g} / \mathrm{ml}$ of Hoechst 33342 (Sigma) to stain the nuclei, and incubated with $2 \mu \mathrm{g} / \mathrm{ml}$ of Calcein (CalbioChem, San Diego, CA, USA) to stain the cytoplasm. After washing with phosphate-buffered saline (PBS), the apoptotic cells were fixed and observed under a Confocal Fluorescence microscope (Leica TCS SMD FCS, Leica, Wetzlar, Germany). The Cell Apoptosis ELISA Detection Kit (Roche, Palo Alto, CA, USA) was used to detect apoptosis in cancer cells with different treatments. The in situ Cell Death Detection Fluorescein Kit (Roche) was used to detect apoptosis in cancer cells after indicated treatments according to the manufacturer's protocol. After treatment, the DNA fragments from cells with different treatments were stained by TUNEL fluorencein; TUNEL positive-stained cells were detected using a confocal fluorescence microscope (Leica).

Immunoprecipitation. Cancer cells with indicated treatments were lysed with

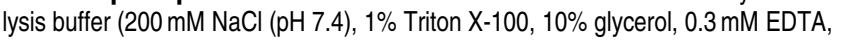


$0.2 \mathrm{mM} \mathrm{Na}_{3} \mathrm{VO}_{4}$ and protease inhibitor cocktails (Roche Diagnostics, Indianapolis, IN, USA). Aliquots of $800 \mu \mathrm{g}$ of proteins from each sample were precleared by incubation with $20 \mu$ of protein A/G Sepharose (beads) (Amersham, IL, USA) for $1 \mathrm{~h}$ at $4{ }^{\circ} \mathrm{C}$. Precleared samples were incubated overnight with specific antibodies in lysis buffer at $4^{\circ} \mathrm{C}$. To this was added $20 \mu \mathrm{l}$ of protein $\mathrm{A} / \mathrm{G}$ beads and the samples were incubated for $2 \mathrm{~h}$ at $4^{\circ} \mathrm{C}$. The beads were washed five times with PBS and once with lysis buffer, boiled, was separated by $10 \%$ SDS-PAGE and transferred onto a PVDF membrane followed by western blotting analysis as described above.

Analysis of intracellular ceramide levels. The total pool of sphingolipids was radiolabeled by growing the cells in the presence of $3 \mu \mathrm{Ci} / \mathrm{ml}\left[{ }^{3} \mathrm{H}\right]$-serine ( $30 \mathrm{Ci} / \mathrm{mmol}$; Amersham), a precursor for sphingolipid biosynthesis. After indicated treatment, the medium was removed and the cells were fixed in ice-cold $\mathrm{CH}_{3} \mathrm{OH}$ followed by lipid extraction from the cells ${ }^{20}$. Aliquots of the lipid extracts were taken for the determination of the total amount of lipid-incorporated radioactivity. Acylglycerolipids were hydrolyzed during 1 h of incubation at $37^{\circ} \mathrm{C}$ in $\mathrm{CHCl}_{3} / \mathrm{CH}_{3} \mathrm{OH}$ $(1: 1, \mathrm{v} / \mathrm{v})$ containing $0.1 \mathrm{M} \mathrm{KOH}$. The remaining lipids were re-extracted and applied on high-performance thin-layer chromatography plates. Plates were developed in $\mathrm{CHCl}_{3} / \mathrm{CH}_{3} \mathrm{OH} / \mathrm{H}_{2} \mathrm{O}(14: 6: 1, \mathrm{v} / \mathrm{v})$ in first dimension and in $\mathrm{CHCl}_{3} / \mathrm{CH}_{3} \mathrm{COOH}$ $(9: 1, v / v)$ in second dimension to resolve ceramide. Ceramide-containing spots were scraped and subjected to scintillation counting. The effects of TSA and inhibitors on ceramides levels were determined by growing the cells, after overnight adherence, for 4 days in medium containing $\left[{ }^{3} \mathrm{H}\right]$ serine. Drugs were present for the last 2-day period or the final $12 \mathrm{~h}$ before the end of incubation. Treatment with $0.1 \mathrm{units} / \mathrm{ml}$ bacterial sphingomyelinase (Sigma) for the final $2 \mathrm{~h}$ of the incubation served as positive control (maximal ceramide formation from sphingomyelin; see ref. 20). Cellular ceramide production was indicated as fold change compared with untreated control.

Plasmids. To generate myc-PP1 expression vectors, PP1 $\alpha$ CDNA was PCR amplified using primer pairs $5^{\prime}$-GGGCTCGAGGCCACCATGTCCGACAGCGAG AAGCTC-3' and 5'-GGGAAGCTTTTTCTTGGCTTTGGCAGAGTT-3' , and a rabbit PP $1 \alpha$ cDNA as a template and subcloned into the $X$ hol and Hindlll sites of pcDNA3 D95N. myc-PP1 mutants were generated using the QuikChange Site-Directed mutagenesis kit (Stratagene, La Jolla, CA, USA) according to the manufacturer's protocol. $^{40}$

RNAi and Plasmid transfection. siRNA for PP1, HDAC6 were purchased from Santa Cruz Biotechnology. L3.6 cells were seeded in a six-well plate one day before transfection and cultured to $60 \%$ confluence the following day in $2 \%$ FBS medium. For RNAi experiments, $4.5 \mu \mathrm{l}$ PLUS reagent (Invitrogen) was diluted in $90 \mu \mathrm{l}$ of RNA dilution water (Invitrogen) for $5 \mathrm{~min}$ in room temperature. Then, $10 \mu \mathrm{l}$ PP1/HDAC6 siRNA $(25 \mu \mathrm{M})$ or control siRNA $(25 \mu \mathrm{M})$ was added to PLUS reagent and left for $5 \mathrm{~min}$ at room temperature. Lipofectamine (4.5 $\mu \mathrm{l})$ (Invitrogen) was then added to the complex. After $30 \mathrm{~min}$ incubation, the transfection complex was formed. Finally, the complex was added to the wells containing $1 \mathrm{ml}$ of medium with the final siRNA concentration of $250 \mathrm{nM}$. PP1/HDAC6 protein expression was determined by western blot at $72 \mathrm{~h}$ after transfection, and only successfully knockdown cells were used for further experiments. For plasmid transfection, $1 \mu \mathrm{g}$ of plasmid was transfected to each well of one six-well plate using the same transfection methods mentioned above.

In vivo human tumor mice xenograft model. L3.6 cells were implanted into the flanks of 6 - to 8 -week-old nude mice $\left(1 \times 10^{6}\right.$ cells/implantation). Once the tumor size reached $50-100 \mathrm{~mm}^{3}$, the animals were randomized into four groups ( $n=10 /$ group): PBS, TSA, C6-ceramide and combination. TSA $(1 \mathrm{mg} / \mathrm{kg})$ was administered intraperitoneally daily for 12 days (the first day of injection counted as day 0$)$, with or without intraperitoneally injections of C6-ceramide $(10 \mathrm{mg} / \mathrm{kg})$ were administered on days 1-6. Tumor volumes and animal survival were monitored two to three times a week. The animals were killed using procedures that were in accordance with institutional regulations. A similar experiment was performed on $\mathrm{CaOV} 3$ tumors. Tumor-bearing mice were randomized into four groups ( $n=10 /$ group). TSA was administered as described earlier and intraperitoneal injections of C6-ceramide were administered on days 1-6. At 4 weeks after treatment with drug, tumor xenografts were freshly removed, lysed using lysis buffer described above, followed by western blot detecting AKT phosphorylation and tubulin acetylation. All animal studies were approved by the institutional review board of China Pharmaceutical University.
Statistical analysis. The values in the figures are expressed as means \pm S.D. The figures in this study were representatives of more than three different experiments. Values of $P<0.05$ were considered as statistically significant (ANOVA) with a Newman-Keuls post test.

\section{Conflict of interest}

The authors declare no conflict of interest.

Acknowledgements. This work was supported by the National Natural Science Foundation of China (No. 81072661, No. 30701032 and No. 30671894), the New Century Excellent Talents Program for Dr. Yong Yang supported by Ministry of Education of China (2009), the Fundamental Research Funds for the Central Universities (No. JKZ2009006), the Natural Science Foundation of Jiangsu Province (No. BK2009298, BK2009459 and BK2010597) and 'Major Drug Discovery' science and technology major projects of China (No. 2009ZX09303-001).

1. Egger G, Liang G, Aparicio A, Jones PA. Epigenetics in human disease and prospects for epigenetic therapy. Nature 2004; 429: 457-463.

2. Jones PA, Baylin SB. The fundamental role of epigenetic events in cancer. Nat Rev Genet 2002; 3: 415-428.

3. Kristensen LS, Nielsen HM, Hansen LL. Epigenetics and cancer treatment. Eur J Pharmacol 2009; 625: 131-142.

4. Kelly WK, O'Connor OA, Krug LM, Chiao JH, Heaney M, Curley T et al. Phase I study of an oral histone deacetylase inhibitor, suberoylanilide hydroxamic acid, in patients with advanced cancer. J Clin Oncol 2005; 23: 3923-3931.

5. Johnstone RW. Histone-deacetylase inhibitors: novel drugs for the treatment of cancer. Nat Rev Drug Discov 2002; 1: 287-299.

6. Lane AA, Chabner BA. Histone deacetylase inhibitors in cancer therapy. J Clin Oncol 2009; 27: $5459-5468$.

7. Juan LJ, Shia WJ, Chen MH, Yang WM, Seto E, Lin YS et al. Histone deacetylases specifically down-regulate p53-dependent gene activation. J Biol Chem 2000; 275 : 20436-20443.

8. Chen CS, Weng SC, Tseng PH, Lin HP, Chen CS. Histone acetylation-independent effect of histone deacetylase inhibitors on Akt through the reshuffling of protein phosphatase 1 complexes. J Biol Chem 2005; 280: 38879-38887.

9. Kurinna SM, Tsao CC, Nica AF, Jiffar T, Ruvolo PP. Ceramide promotes apoptosis in lung cancer-derived A549 cells by a mechanism involving c-Jun NH2-terminal kinase. Cancer Res 2004; 64: 7852-7856.

10. Ogretmen B, Hannun YA. Biologically active sphingolipids in cancer pathogenesis and treatment. Nat Rev Cancer 2004; 4: 604-616.

11. Bose R, Verheij M, Haimovitz-Friedman A, Scotto K, Fuks Z, Kolesnick R. Ceramide synthase mediates daunorubicin-induced apoptosis: an alternative mechanism for generating death signals. Cell 1995; 82: 405-414.

12. Mathias S, Pena LA, Kolesnick RN. Signal transduction of stress via ceramide. Biochem J 1998; 335(Part 3): 465-480.

13. Myrick D, Blackinton D, Klostergaard J, Kouttab N, Maizel A, Wanebo $\mathrm{H}$ et al. Paclitaxelinduced apoptosis in Jurkat, a leukemic $T$ cell line, is enhanced by ceramide. Leuk Res 1999; 23: 569-578.

14. Mehta S, Blackinton D, Omar I, Kouttab N, Myrick D, Klostergaard J et al. Combined cytotoxic action of paclitaxel and ceramide against the human Tu138 head and neck squamous carcinoma cell line. Cancer Chemother Pharmacol 2000; 46: 85-92.

15. Deshpande D, Devalapally $H$, Amiji M. Enhancement in anti-proliferative effects of paclitaxel in aortic smooth muscle cells upon co-administration with ceramide using biodegradable polymeric nanoparticles. Pharm Res 2008; 25: 1936-1947.

16. Qiu L, Zhou C, Sun Y, Di W, Scheffler E, Healey S et al. Paclitaxel and ceramide synergistically induce cell death with transient activation of EGFR and ERK pathway in pancreatic cancer cells. Oncol Rep 2006; 16: 907-913.

17. Yamashita Y, Shimada M, Harimoto N, Rikimaru T, Shirabe K, Tanaka S et al. Histone deacetylase inhibitor trichostatin $\mathrm{A}$ induces cell-cycle arrest/apoptosis and hepatocyte differentiation in human hepatoma cells. Int J Cancer 2003; 103: 572-576.

18. Rahmani M, Reese E, Dai Y, Bauer C, Payne SG, Dent P et al. Coadministration of histone deacetylase inhibitors and perifosine synergistically induces apoptosis in human leukemia cells through Akt and ERK1/2 inactivation and the generation of ceramide and reactive oxygen species. Cancer Res 2005; 65: 2422-2432.

19. Elojeimy S, Holman DH, Liu X, El-Zawahry A, Villani M, Cheng JC et al. New insights on the use of desipramine as an inhibitor for acid ceramidase. FEBS Lett 2006; 580: 4751-4756.

20. Veldman RJ, Klappe K, Hoekstra D, Kok JW. Metabolism and apoptotic properties of elevated ceramide in HT29rev cells. Biochem J 1998; 331(Part 2): 563-569.

21. Babia T, Veldman RJ, Hoekstra D, Kok JW. Modulation of carcinoembryonic antigen release by glucosylceramide-implications for HT29 cell differentiation. Eur J Biochem 1998; 258: 233-242. 
22. Tettamanti G. Ganglioside/glycosphingolipid turnover: new concepts. Glycoconj J 2004; 20: $301-317$.

23. Reynolds CP, Maurer BJ, Kolesnick RN. Ceramide synthesis and metabolism as a target for cancer therapy. Cancer Lett 2004; 206: 169-180.

24. Sietsma H, Veldman RJ, Kolk D, Ausema B, Nijhof W, Kamps W et al. 1-phenyl-2decanoylamino-3-morpholino-1-propanol chemosensitizes neuroblastoma cells for taxol and vincristine. Clin Cancer Res 2000; 6: 942-948.

25. Radin NS, Shayman JA, Inokuchi J. Metabolic effects of inhibiting glucosylceramide synthesis with PDMP and other substances. Adv Lipid Res 1993; 26: 183-213.

26. Dobrowsky RT, Kamibayashi C, Mumby MC, Hannun YA. Ceramide activates heterotrimeric protein phosphatase 2A. J Biol Chem 1993; 268: 15523-15530.

27. Law $B$, Rossie $S$. The dimeric and catalytic subunit forms of protein phosphatase $2 A$ from rat brain are stimulated by C2-ceramide. J Biol Chem 1995; 270: 12808-12813.

28. Wolff RA, Dobrowsky RT, Bielawska A, Obeid LM, Hannun YA. Role of ceramide-activated protein phosphatase in ceramide-mediated signal transduction. J Biol Chem 1994; 269 : 19605-19609.

29. Kishikawa K, Chalfant CE, Perry DK, Bielawska A, Hannun YA. Phosphatidic acid is a potent and selective inhibitor of protein phosphatase 1 and an inhibitor of ceramidemediated responses. J Biol Chem 1999; 274: 21335-21341.

30. Dowdy SC, Jiang S, Zhou XC, Hou X, Jin F, Podratz KC et al. Histone deacetylase inhibitors and paclitaxel cause synergistic effects on apoptosis and microtubule stabilization in papillary serous endometrial cancer cells. Mol Cancer Ther 2006; 5: 2767-2776.

31. Marcus Al, Zhou J, O'Brate A, Hamel E, Wong J, Nivens M et al. The synergistic combination of the farnesyl transferase inhibitor lonafarnib and paclitaxel enhances tubulin acetylation and requires a functional tubulin deacetylase. Cancer Res 2005; 65: 3883-3893.

32. Blagosklonny MV, Robey R, Sackett DL, Du L, Traganos F, Darzynkiewicz Z et al. Histone deacetylase inhibitors all induce p21 but differentially cause tubulin acetylation, mitotic arrest, and cytotoxicity. Mol Cancer Ther 2002; 1: 937-941.
33. Brush MH, Guardiola A, Connor JH, Yao TP, Shenolikar S. Deactylase inhibitors disrupt cellular complexes containing protein phosphatases and deacetylases. J Biol Chem 2004; 279: 7685-7691.

34. Hubbert C, Guardiola A, Shao R, Kawaguchi Y, Ito A, Nixon A et al. HDAC6 is a microtubule-associated deacetylase. Nature 2002; 417: 455-458.

35. Lim Y, Han I, Kwon HJ, Oh ES. Trichostatin A-induced detransformation correlates with decreased focal adhesion kinase phosphorylation at tyrosine 861 in ras-transformed fibroblasts. J Biol Chem 2002; 277: 12735-12740.

36. Matsuyama A, Shimazu T, Sumida Y, Saito A, Yoshimatsu Y, Seigneurin-Berny D et al. In vivo destabilization of dynamic microtubules by HDAC6-mediated deacetylation. EMBO J 2002; 21: 6820-6831.

37. Liao H, Li Y, Brautigan DL, Gundersen GG. Protein phosphatase 1 is targeted to microtubules by the microtubule-associated protein Tau. J Biol Chem 1998; 273 21901-21908.

38. Metz RJ, Vellody K, Patel S, Bergstrom R, Meisinger J, Jackson J et al. Vitamin D3 and ceramide reduce the invasion of tumor cells through extracellular matrix components by elevating protein phosphatase-2A. Invasion Metastasis 1996; 16: 280-290.

39. Debret R, Brassart-Pasco S, Lorin J, Martoriati A, Deshorgue A, Maquart FX et al. Ceramide inhibition of MMP-2 expression and human cancer bronchial cell invasiveness involve decreased histone acetylation. Biochim Biophys Acta 2008; 1783: 1718-1727.

40. Gallego $M$, Kang $H$, Virshup DM. Protein phosphatase 1 regulates the stability of the circadian protein PER2. Biochem J 2006; 399: 169-175.

Cell Death and Disease is an open-access journal published by Nature Publishing Group. This work is licensed under the Creative Commons Attribution-Noncommercial-No Derivative Works 3.0 Unported License. To view a copy of this license, visit http://creativecommons.org/licenses/by-nc-nd/3.0/

\section{Supplementary Information accompanies the paper on Cell Death and Disease website (http://www.nature.com/cddis)}

